\title{
Thermal Desorption of He Implanted into Ge
}

\author{
M. Turek ${ }^{a *}$, A. Droździel ${ }^{a}$, K. PyszniaK ${ }^{a}$, S. Prucnal, J. ŻuK ${ }^{a}$ And Y. VAganov ${ }^{b}$ \\ ${ }^{a}$ Institute of Physics, Maria Curie Sklodowska University in Lublin, \\ Pl. M. Curie-Sklodowskiej 1, 20-031 Lublin, Poland \\ ${ }^{b}$ Joint Institute for Nuclear Research, Joliot-Curie 6, Dubna, Russia
}

The thermal desorption spectrometry (TDS) measurements of He implanted with the energies $80 \mathrm{keV}$ and $100 \mathrm{keV}$ into Ge was considered. The release of the noble gas took place at temperature range 600-950 K. The TDS spectra had a form of a very wide peak consisting of two parts which means that one deals with two states of He into Ge. No surface blistering or formation of craters was observed after the annealing of the samples implanted with the fluence $1 \times 10^{16} \mathrm{~cm}^{-2}$. the critical fluence needed for bubble formation in Ge is higher than for $\mathrm{Si}$. The analysis of the peak shift with the heating ramp rate allows estimation of desorption activation energies. They are close to $0.8 \mathrm{eV}$ for both peaks $(100 \mathrm{keV})$ while the energy for the second peak in the case of $E=80 \mathrm{keV}$ was more than twice higher.

DOI: 10.12693/APhysPolA.136.285

PACS/topics: 68.43.Vx, 61.72.uf

\section{Introduction}

Implantation of noble gases into solids may induce important modifications of their properties, like forming bubbles i.e. gas-filled voids. Such process was intensively studied in metals [1-3], thin layers [4, 5], and also in semiconductors, as the phenomenon plays a crucial role for Smart-cut processing [6] and gettering of impurities [7, 8].

Thermal desorption spectroscopy (TDS) is a very popular technique employed for studies of diffusion, desorption, and gas trapping by lattice defects like vacancies and vacancy clusters [9]. It is escpecially important for radiation induced damage studies of reactor materials like $\mathrm{Be}[10], \mathrm{W}[11]$, or graphite [12]. It is also useful for investigation of inert gas (mostly He) bubble behaviour formed due to high-fluence ion implantation to silicon [13-16], with a special attention paid to the factors like implantation and annealing regime or additional $\mathrm{H}+$ irradiation [15]. A lot of effort was made to describe bubble formation and gas release by computer modelling [16-20] using e.g. molecular dynamic methods. Although He seems to be the most popular gas used in the TDS studies (due to its mobility) much effort was made using Ar implanted to $\mathrm{Si}$ in a wide range of energies [21-23]. It should be also mentioned that release of heavier inert gases characterised by larger atomic radii and desorption activation energies from $\mathrm{Si}$ was also under investigations [24-26]

After years of standstill germanium attracts attention as a possible semiconductor of the future, mostly due to its high carrier mobility as well as similarities to ,her brother" [27] silicon, which gives a chance for integration with the contemporary CMOS technology. Formation of inert gas bubbles in this material could be especially

*corresponding author; e-mail: mturek@kft.umcs.lublin.pl important for manufacturing of GeOI (germanium on insulator) wafers in a process resembling the Smart-cut. The investigations of He bubbles formation in Ge as well as of helium release due to electron impact were presented in [28]. It was shown that the high-fluence $\left(5 \times 10^{16} \mathrm{~cm}^{-2}\right)$ irradiation with $30 \mathrm{keV} \mathrm{He}{ }^{+}$ions leads to formation of bubbles of a diameter of 1-2 nm. Surface blistering was also observed after the $60 \mathrm{keV} \mathrm{H}$ implantation (fluences up to $10^{17} \mathrm{~cm}^{-2}$ ) followed with the annealing in the temperature range $200-350{ }^{\circ} \mathrm{C}$ [29].

This paper presents the results of TDS measurements of He implanted (100 and $80 \mathrm{keV}$ ) to the germanium samples with smaller fluences $\left(1 \times 10^{16} \mathrm{~cm}^{-2}\right)$ than in [30], still large enough to lead to bubble formation in the case of Si. The TDS spectra collected for both implantation energies using the heating ramp rates in the range $0.45 \mathrm{~K} / \mathrm{s}$ up to $1.5 \mathrm{~K} / \mathrm{s}$ are presented and discussed. Desorption activation energies are calculated from the peak shifts using the Redhead method. A brief presentation of the experimental setup and procedures is also given for completeness.

\section{Experimental}

The germanium samples (orientation 110) were implanted with $\mathrm{He}^{+}$ions with the energies $100 \mathrm{keV}$ and $80 \mathrm{keV}$. The implantation fluence was $1 \times 10^{16}$ in both cases. The implantation current density was kept at the level $\sim 1 \mu \mathrm{A} / \mathrm{cm}^{2}$. The samples were irradiated at room temperature.

The thermal desorption spectrometer used during the measurements was described in details in our previous papers [24-26, 30]. Some brief description is given for the sake of completeness. The schematic view of the device is shown in Fig. 1. The main chamber of the spectrometer is made of stainless steel and contains the sample holder/heater (HTR1002 Boralectric, Momentive, Strongsville OH, USA) surrounded by molibdenum and stainless steel screens that reduce heating 
of the chamber wall as well as deposition of solid sample vapours at the other parts of equipment. The heater is connected to the EA-PS 8080T (EA-Electro-Automatik $\mathrm{GmbH}$, Viersen, Germany) programmable power supply. The sample temperature is measured by the K-type thermocouple placed inside the holder, hence the maximum temperature achievable in such configuration is $\sim 1600 \mathrm{~K}$. A pyrometer could be, however, used for alternative temperature measurements. Both programmable power supply and thermal couple (via Hewlett-Packard 34970A data acquisition switch) are connected to a PC microcomputer that controls heating profile employing the PID alghorithm-based controller. The TDS signal is measured by the quadruple mass spectrometer QMG 220 M (Pfeiffer Vacuum, Asslar, Germany) with the secondary electron multiplier detector characterised by the much lower (two orders of magnitude) detection threshold than the previously used equipment with a Faraday cup.

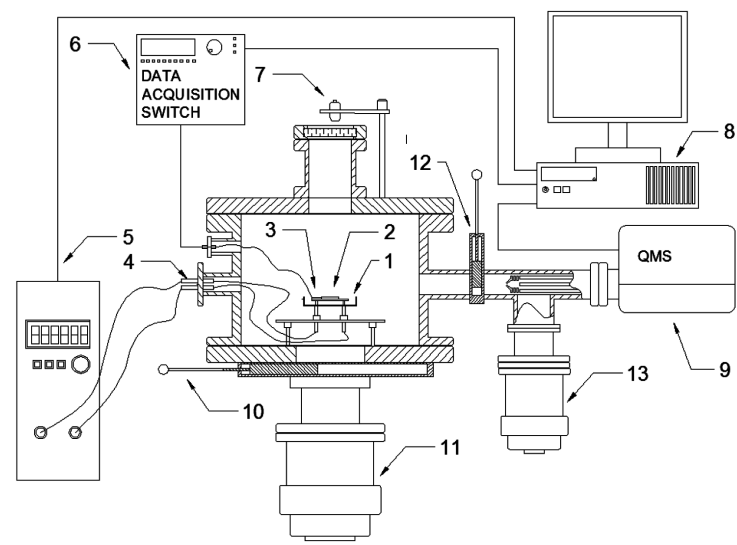

Fig. 1. Schematic drawing of the setup: 1 - sample heater, 2 - sample, 3 - thermocouple, 4 - electrical feedthrough, 5 - programmable heater power supply, 6 - data acquisition switch, 7 - pyrometer, 8 - PC, 9 - quadruple mass spectrometer, 10, 12 - gatevalve, 11, 13 - turbomolecular pumps.

As can be seen in Fig. 1, two turbomolecular pumps are connected to the main chamber via the gate valves. Both pumps provide the base pressure of the order $10^{-8}$ mbar during the device start-up. During the measurement phase the main gate valve is closed and the vacuum is provided by the pump near QMS. It should be noticed that in the current configuration the QMS is much further from the heater. This reduces the deposition of substrate vapours on the QMS parts and makes maintenance easier. Now the typical size of the sample is reduced to $0.25-0.5 \mathrm{~cm}^{2}$ which makes uniform sample heating easier. The TDS signal of He released from the sample is registered by the Quadera ${ }^{T M}$ software controlling the QMS.

The linear ramp rate profile was used during the described measurements

$$
T(t)=T_{o}+\beta t,
$$

where $T_{o}$ is the room temperature and $\beta$ is the ramp rate kept in the range $0.4-1.5 \mathrm{~K} / \mathrm{s}$.

\section{Results}

The depth profiles of He implanted into Ge and produced vacancies are shown in Fig. 2. The calculations were performed using the SRIM software [31]. The projected implantation ranges were $410 \mathrm{~nm}(80 \mathrm{keV})$ and $490 \mathrm{~nm}(100 \mathrm{keV})$, being comparable to that obtained for tilted $\left(45^{\circ}\right)$ He implantation to Si [30] due to the differences in target density. Also the maximum dopant concentrations are comparable. The depths of the maximum vacancy concentration are $\sim 80 \%$ smaller than the projected ranges of $\mathrm{He}^{+}$ions.
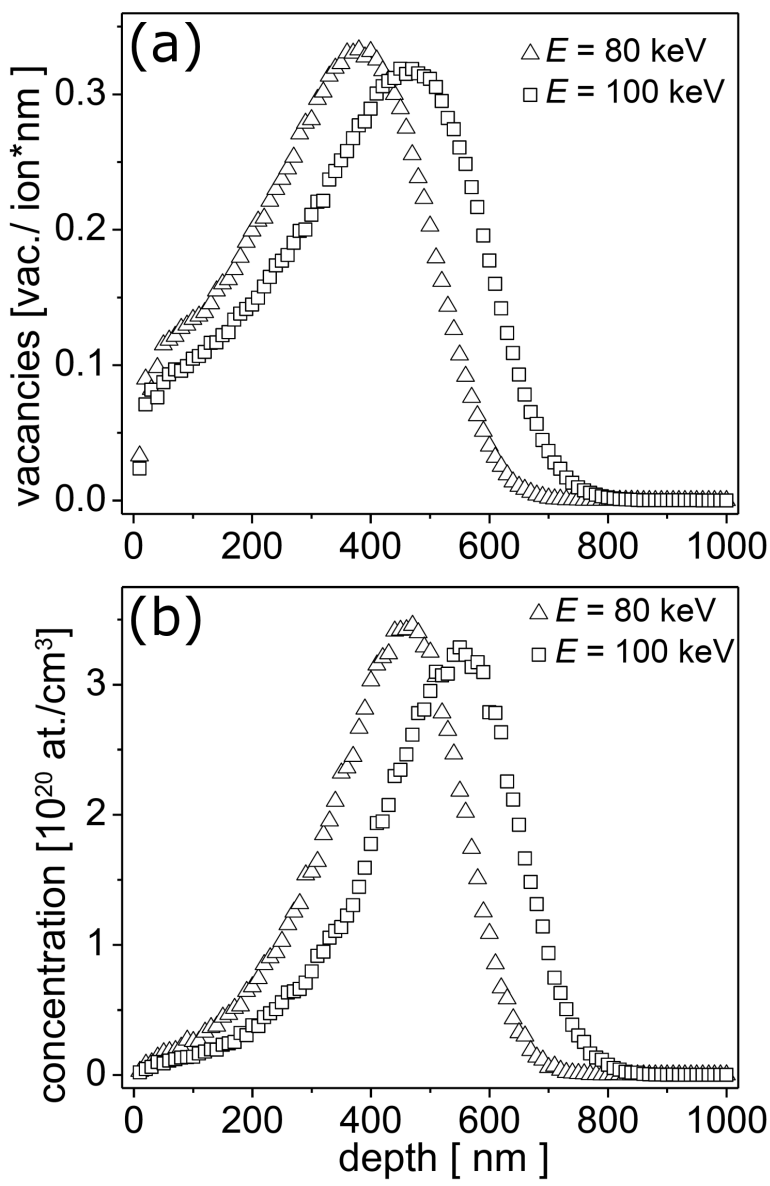

Fig. 2. (a) Vacancies distributions and (b) concentration of He implanted in Ge calculated using the SRIM code.

The thermal desorption spectra are shown in Fig. 3a $(E=100 \mathrm{keV})$ and Fig. 3b $(E=80 \mathrm{keV})$. Additionaly, the peak positions are listed in Table I. The He signal was observed in the range $600-1000 \mathrm{~K}$ in a form of very broad release ( $\sim 200-250 \mathrm{~K}$ FWHM) consisting of at least two peaks. The distance between the two peaks is approximately $100 \mathrm{~K}$. The He release takes place in approximately the same range as it was observed for implanted Si. There are, however some major differences. First of all, the first (lower temperature) release of $\mathrm{He}$ was dominant a one and had a form of rather narrow 
peak ( $<50 \mathrm{~K}$ FWHM) followed by a wide low ridge. In the case of He implanted to Ge one observes two very broad peaks of approximately the same intensity. One may suspect that at least one of the He releases from implanted Ge can be assigned to He bubble growth as that process is directly confirmed by transmission electron microscopy [20]. It should be, however, kept in mind that no craters or embrittlement signs were observed using optical microscope in the case of He implanted and annealed samples, while in the case of $1 \times 10^{16} \mathrm{~cm}^{-2} \mathrm{He}$ implanted Si a lot of ruptures, cracks and craters were clearly seen [30].

\section{(a)}
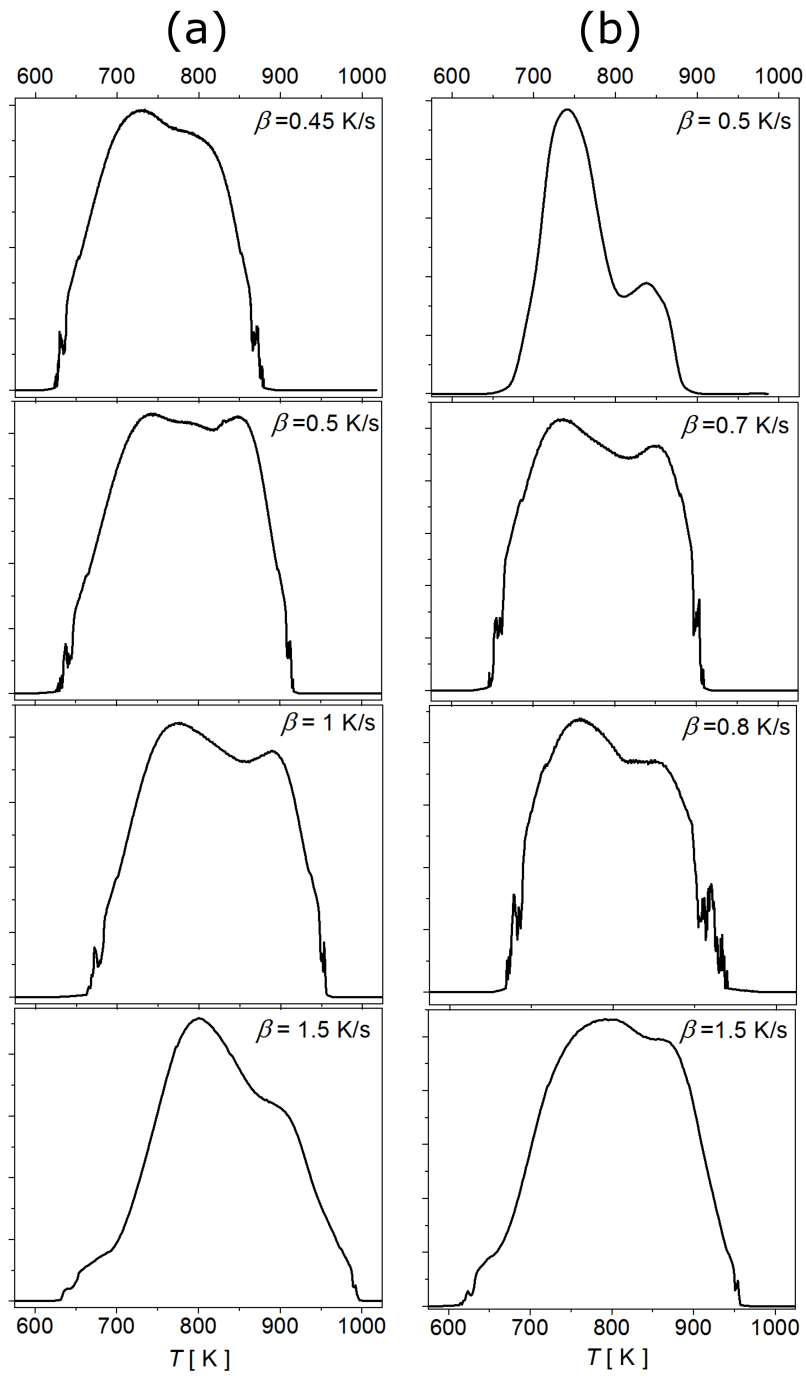

Fig. 3. The TDS spectra measured for (a) $100 \mathrm{keV}$ and (b) $80 \mathrm{keV} \mathrm{He}^{+}$implanted Ge samples.

Therefore one may suspect that in the case of Ge, the implantation fluence of the order $1 \times 10^{16} \mathrm{~cm}^{-2}$ is below the critical value that enables formation of large and stable pressurized He bubbles [32] which are supposed to be formed after some large enough clusters of vaccancies (4 in the case of $\mathrm{Si}$ ) are obtained [33] and the phase transition of He atoms in the solid solution to He in the gas
Postions of He release peaks and desorption

TABLE I activation energies for the two implantation energies

\begin{tabular}{c|c|c|c|c|c}
\hline \hline$E[\mathrm{keV}]$ & $\beta[\mathrm{K} / \mathrm{s}]$ & \multicolumn{2}{|c|}{$T_{p}[\mathrm{~K}]$} & \multicolumn{2}{|c}{$Q[\mathrm{eV}]$} \\
\hline \multirow{3}{*}{100} & 0.45 & 730 & 825 & & \\
& 0.5 & 740 & 840 & $0.78 \pm 0.07$ & $0.74 \pm 0.17$ \\
& 1 & 774 & 891 & & \\
& 1.5 & 801 & 910 & & \\
80 & 0.5 & 737 & 837 & & \\
& 0.7 & 738 & 853 & $0.75 \pm 0.13$ & $1.9 \pm 0.5$ \\
& 0.8 & 760 & 862 & & \\
& 1.5 & 797 & 873 & &
\end{tabular}

phase inside the vacancy clusters takes place. One should also keep in mind that the bubble formation and blistering of $\mathrm{H}$ implanted $\mathrm{Ge}$ required implantation fluencies in the range from $3 \times 10^{16} \mathrm{~cm}^{-2}$ up to $1 \times 10^{17} \mathrm{~cm}^{-2}$ for smaller $(60 \mathrm{keV})$ implantation energy.

A very broad shape of the He release may suggest that lower temperature release is related to the dissolved He effusion from interstitials, vacancies, and unstable $\mathrm{He}_{n} \mathrm{~V}_{m}$ clusters [14, 34]. Consequently, the second release could originate from the small vacancy clusters - He trapped in such small clusters is highly pressurised [14] due to quantum effects and release could take place at lower temperatures than in the case of large bubbles [30]. When He is released, vacancy clusters recombine with interstitials which prevents large bubbles to be formed.

The presence of two peaks separated by several tens of $\mathrm{K}$ being a sign of two different states of inert gas presence in the matrix was observed in the case of $\operatorname{Ar}[24]$, $\mathrm{Kr}$ [25], and Xe [26] implanted into Si. In the latter case the peak widths and separation of the two releases strongly depend on implantation energy - in the case of $E=150 \mathrm{keV}$ for a single broad peak.

The position of the release peaks shifts towards higher temperatures with the increasing ramp rate which is of implanted gas dopant release. The effect is approximately the same as in the case of both considered implantation energies. The first peak is shifted by $\sim 60 \mathrm{~K}$ when $\beta$ increases from $0.5 \mathrm{~K} / \mathrm{s}$ to $1.5 \mathrm{~K} / \mathrm{s}$ while a large difference can be observed for the second peak ( $80 \mathrm{~K}$ for the higher energy while only $20 \mathrm{~K}$ for the lower one).

Analysis of the peak shift using the Redhead approach [35] enables estimation of desorption activation energies. In the case of the first order process the PolanyiWigner equation describing the measured TDS signal has the form

$$
\frac{\mathrm{d} n}{\mathrm{~d} t}=-\gamma n \exp \left(-\frac{Q}{k_{\mathrm{B}} T}\right),
$$

where $n$ is the surface density of the desorbing substance, $k_{\mathrm{B}}$ is the Boltzmann constant, $Q$ is the desorption activation energy, and $\gamma$ is the pre-exponential factor. Keeping in mind that the temperature increases with time at the constant rate and denoting the temperature corresponding to the peak as $T_{p}$, one gets from the condition $\mathrm{d}^{2} n / \mathrm{d} t^{2}=0$ (at the peak position) the relationship 


$$
\frac{1}{T_{p}}=\frac{k_{\mathrm{B}}}{Q} \ln \left(\frac{T_{p}^{2}}{\beta}\right)+\frac{k_{\mathrm{B}}}{Q} \ln \left(\gamma \frac{k_{\mathrm{B}}}{Q}\right) .
$$

It can be easily seen that the diffusion activation energy $Q$ is obtained from the slope of the $1 / T_{p}$ vs. $\ln \left(T_{p}^{2} / \beta\right)$ plot using e.g. the least squares fit. The calculated values of desorption activation energy for both peaks are gathered in Table I. They are close to the detrapping energy of $\mathrm{He}$ in $\mathrm{Ge}(\sim 1 \mathrm{eV})$ obtained using the energetic electron beam as a probe [28]. It should be also mentioned that the presence of two different activation energies (of the order $0.7 \mathrm{eV}$ and $2 \mathrm{eV}$ ) was shown during the studies of Ge blistering after $\mathrm{H}$ irradiation with the fluences $\sim 3 \times 10^{16} \mathrm{~cm}^{-2}[29]$.

The obtained activation energy values are lower than those measured for He release from $\mathrm{Si}$, especially defected one $(1-1.3 \mathrm{eV})$ [30], and of the activation energies for heavier noble gases in the $\mathrm{Si}$ matrix reaching $2 \mathrm{eV}$ for $\mathrm{Kr}[25]$ and more than $3 \mathrm{eV}$ in the case of Xe [26]. One can expect that the desorption activation energies for heavier noble gases are also higher than those in the case of He. A good question concerns the release temperatures of very heavy noble gases from Ge. In the case of $\mathrm{Xe}$ in $\mathrm{Si}$ the release temperatures are very close to the Si melting point, which is much lower for Ge $(1211 \mathrm{~K})$. Such measurements will be the aim of our future investigations. It is also planned to test the change of TDS spectra with the He irradiation fluence. Increasing the fluence towards $1 \times 10^{17} \mathrm{~cm}^{-2}$ is expected to lead to very distinct and sudden releases of He from the stable pressurized bubbles resulting also in modification of Ge surface morphology. The influence of amorphisation (e.g. by means of the auto-implantation like in [30]) on He bubble formation and TDS release seems to be worth of further studies.

\section{Conclusions}

The TDS measurement results of helium released from the He implanted $(E=100 \mathrm{keV}$ and $E=80 \mathrm{keV})$ Ge samples are presented in the paper. The spectra were collected for the temperature ramp rates from $0.45 \mathrm{~K} / \mathrm{s}$ up to $1.5 \mathrm{~K} / \mathrm{s}$. A very broad peak was observed in the temperature range $600-950 \mathrm{~K}$. It consists of two parts, probably corresponding to the releases of $\mathrm{He}$ dissolved in $\mathrm{Ge}$ (e.g. in interstitial positions) or prebubble He filled vacancy clusters. No surface damage like cracks, craters, or blistering was observed after the annealing. Hence one may assume that the applied implantation influence $\left(1 \times 10^{16} \mathrm{~cm}^{-2}\right)$ in the case of Ge was below the critical value that results in pressurised He bubble formation. The analysis of the peak position shifts enabled estimation of desorption activation energies according to the Redhead scheme. The estimated values $(\sim 0.8 \mathrm{eV})$ coincide with detrapping energies determined using the electron beam bombardment of He filled cavities in Ge.

\section{Acknowledgments}

This work was supported by the National Science Centre under the Grant No. 2016/23/B/ST7/03451.

\section{References}

[1] K.T. Westerduin, A.V. Veen, O. Dankert, A.A. Kamperman, J.J.F. Scheffer, H. Galenkamp, J. Zijp, Vacuum 49, 31 (1998).

[2] O. Morozov, V. Zhurba, I. Neklyudov, O. Mats, A. Rud, N. Chernyak, V. Progolaieva, Nanoscale. Res. Lett. 10, 154 (2015).

[3] H. Trinkaus, B.N. Singh, J. Nucl. Mater. 323, 229 (2003).

[4] S. Chang, T. Lin, T. Li, J. Nanomater. 2014, 690498 (2014).

[5] V. Venugopal, B.J. Thijsse, J. Phys. D: Appl. Phys. 42, 165412 (2009).

[6] M. Bruel, B. Aspar, B. Charlet, C. Maleville, T. Poumeyrol, A. Soubie, A.J. Auberton-Herve, J.M. Lamure, T. Barge, in: Proc. IEEE Inter. SOI Conference, 1995 p. 178.

[7] R. Kögler, A. Peeva, A.Lebedev, M. Posselt, W. Skorupa, G. Oezelt, H. Hutter, M. Behar, J. Appl. Phys. 94, 3834 (2003).

[8] V. Raineri, M. Saggio, E. Rimini, J. Mater. Res. 15, 1449 (2000).

[9] A.A.V. Gorkum, E.V. Kornelsen, Vacuum 31, 89 (1981).

[10] M. Zibrov, Y. Gasparyan, S. Ryabtsev, A. Pisarev, Phys. Procedia 71, 83 (2015).

[11] V.K. Alimov, B. Tyburska-Püschel, S. Lindig, Y. Hatano, M. Balden, J. Roth, K. Isobe, M. Matsuyama, T. Yamanishi, J. Nucl. Mater. 420, 519 (2012).

[12] A.A. Airapetov, L.B. Begrambekov, S.V. Vergazov, A.A. Kuzmin, O.C. Fadina, P.A. Shigin, J. Surf. Invest. X-Ray Synchrotron Neutron Tech. 4, 567 (2010).

[13] E. Oliviero, M.L. David, M.F. Beaufort, J.F. Barbot, A.V. Veen, Appl. Phys. Lett. 81, 4201 (2002).

[14] F. Corni, G. Calzolari, F. Gambetta, C. Nobili, R. Tonini, M. Zapparoli, Mater. Sci. Eng. B 71, 207 (2000).

[15] G.F. Cerofolini, G. Calzolari, F. Corni, S. Frabboni, C. Nobili, G. Ottaviani, R. Tonini, Phys. Rev. B 61, 10183 (2000).

[16] S. Godey, E. Ntsoenzok, T. Sauvage, A.V. Veen, F. Labohm, M.F. Beaufort, J.F. Barbot, Mater. Sci. Eng. B 73, 54 (2000).

[17] Y. Zhang, P.C. Millett, M. Tonks, L. Zhang, B. Biner, J. Phys. Condens. Matter. 24, 305005 (2012).

[18] M. Hasanuzzaman, Y.M. Haddara, A.P. Knights, J. App. Phys. 112, 064302 (2012).

[19] L. Pizzagalli, M.L. David, M. Bertolus, Model. Simul. Mater. Sci. Eng. 21, 065002 (2013).

[20] A. Charaf Eddin, L. Pizzagalli, J. Phys. Condens. Matter 24, 175006 (2012). 
[21] W.M. Lau, 1. Bello, L.J. Huang, X. Feng, M. Vos, I.V. Mitchell, J. Appl. Phys. 74, 7105 (1993).

[22] A. Filius, A.V. Veen, K.R. Bijkerk, J.H. Evans, Radiat. Eff. 108, (1989).

[23] R. Hanada, S. Saito, S. Nagata, S. Yamaguchi, T. Shinozuka, I. Fujioka, Mat. Sci. Forum 196, 1375 (1995).

[24] A. Drozdziel, A. Wojtowicz, M. Turek, K. Pyszniak, D. Maczka, B. Slowinski, Y.V. Yushkevich, J. Zuk, Acta Phys. Pol. A 125, 1400 (2014).

[25] M. Turek, A. Droździe1, A. Wójtowicz, J. Filiks, K. Pyszniak, D. Mączka, Y. Yuschkevich, Acta Phys. Pol. A 132, 249 (2017).

[26] M. Turek, A. Droździel, K. Pyszniak, A. Wójtowicz, Y. Vaganov, Przeglad Elektrotechniczny 2018-7, 159 (2018).

[27] J. Vanhellemont, E. Simoen J. Electrochem. Soc. 154, H572 (2007).

[28] M.L. David, K. Alix, F. Pailloux, V. Mauchamp, M. Couillard, G.A. Botton, L. Pizzagalli J. Appl. Phys. 115, 123508 (2014).
[29] F. Yang, X.X. Zhang T.C. Ye, S.L. Zhuang, J. Electrochem. Soc. 158, H1233 (2011).

[30] M. Turek, A. Droździel, K. Pyszniak, A. Wójtowicz, D. Mączka, Y. Yuschkevich, Y. Vaganov, J. Żuk, Acta. Phys. Pol. A 128, 849 (2015).

[31] J.F. Ziegler, M.D. Ziegler, J.P. Biersack, Nucl. Instr. Meth. B 268, 1818 (2010).

[32] M. Hasanuzzaman, Ph.D. Thesis, McMaster University, 2012.

[33] B. Pivac, O. Milat, P. Dubček, S. Bernstorff, F. Corni, C. Nobili, R. Tonini, Phys. Stat. Sol. A 198, 29 (2003).

[34] F. Corni, C. Nobili, G. Ottaviani, R. Tonini, G. Calzolari, G.F. Cerofolini, G. Queirolo, Phys. Rev. $B$ 56, 7331 (1997).

[35] P.A. Redhead, Vacuum 12, 203 (1962). 